\title{
Universality and Singularities of Sports Shows Production
}

\begin{abstract}
By Patrice Bouvet ${ }^{*}$
After recalling that the production of a sports event, like any production, follows a wave-like pattern, the three phases of said production will be distinguished: preparation/reflection, actualization, finalization. The point of this distinction lies in that: respectively competitive balance, "competitive exceptionality", and competitive stakes. The former takes into account the difference between the percentages of the completed skills and the permanence of such skills which set apart the professional from the amateur players. The latter is defined as the sum of the monetizable stakes and the direct economic stakes. Hence, as the producers of sports events mainly market four types of rights, we may suggest a new analysis of the monetization of sports events.
\end{abstract}

Keywords: monetization, production, results, sports economics, sports events.

\section{Introduction}

The multiplication of scientific articles ${ }^{1}$ and media debates on these issues attests to this: the economics of sport is a growing discipline. Logically, since it is now largely "monetized", professional sport most often attracts the attention of researchers and commentators. However, in the end, what do professional athletes produce? The answer is now well known: a live performance with certain particularities.

The term "production" is frequently used in economics but also in everyday vocabulary. Nevertheless, its definition often remains vague. Thus, for example, "production" refers indistinctly to the action that gives rise to the goods and services and the result of that action (the finished product). In the past, various answers have been given to the question of what to produce. For mercantilists, production essentially means mining precious metals. For physiocrats, only agriculture is productive. Later, Smith (1776) was the first to refute this view and to show the productive nature of manufactured works. Gradually the notion of production has broadened. Today in economic dictionaries (Echaudemaison 1996, p.351) it is defined as: "the act of manufacturing goods or making available to others, services that satisfy individual or collective goods, generally solvent".

According to this definition, production would be the domain of engineers, technicians and workers responsible for manufacturing and developing goods and services. Yet, as we have just recalled, economists have long since taken hold of the concept. Why? Because in reality humans are incapable of creating or destroying the slightest particle of matter. Whatever the goods or services, through

\footnotetext{
${ }^{*}$ Lecturer, University of Poitiers, France.

${ }^{1}$ On this point see, particularly the articles published in the Journal of Sports Economics and the International Journal of Sport Finance.
} 
a series of operations that are all reduced to simple "displacements", man borrows from the environment in which he lives the materials. The question of the relationship of these trips to time is therefore fundamental. This is the case in the production of sports shows as it is for all other productions. The latter seems more complex to study since it requires the cooperation of many producers: organizers, players or clubs and broadcasters, themselves in contact with other actors; fans and advertisers mainly. In addition, several "sports times" can be distinguished: the match, which will be the subject of our study here, a series of matches (round trip for example), a particular competition, a "season" or several seasons. Despite these specificities, some authors (Scully 1974, Gustafson et al. 1999, Borland 2006) have used factor theory to estimate a team's output. From this perspective, the match, the output, is the product of the combination of work (players, staff) and capital (stadium, other equipment), inputs. This type of analysis makes it possible to estimate the marginal productivity of players and compare team performance. In addition to certain difficulties, particularly to take into account the interactions between players, by definition this method does not focus on the entire production process (role of other actors) and ignores the temporal dimension of any production. This is one of the reasons that led us to consider this reflection.

In what follows, we will therefore endeavour to present the universal character of the production of sports shows, especially in its relation to time, then to highlight its many singularities. To this end, after having shown that economic production $^{2}$ is a "wave phenomenon" (I), we will focus on the peculiarities of the production of sports shows (II), characteristics which greatly determine its possibilities of valorisation (III).

\section{Economic Production: A "Wave Phenomenon"}

\section{Prerequisites for Production}

Making a computer, developing a cooking recipe, building a dam, organizing a sports show... and in general everything that is produced by man is produced after a "reflection-preparation" phase, usually long and complicated depending on the nature of the good or service produced. Therefore in the previous examples, it is respectively necessary to design and choose the different components, to procure and assemble the different ingredients, to choose the site and make the plans, to determine the place and define the rules of the match, even if this phase of "reflection-preparation" may be elementary and of short duration no production deviates from this rule. This first observation is obvious. It is nevertheless important because it makes it possible clearly distinguishing this preparatory phase from the actual implementation phase from the production phase, which is not creative. Indeed, apart from the imaginary (thought and art), human is not a creator. In accordance with the Lavoisier principle, the actions successively implemented to produce "transform" matter or energy. Frequently, this

\footnotetext{
${ }^{2}$ What we oppose to material production.
} 
transformation $^{3}$ takes place in different phases: to produce more efficiently, people acquire "tools" that enable them to obtain productivity gains. These tools can be very different, they correspond to the material capital which, associated with work and nature, apparently constitute the "factors of production".

They consist of technical instruments used to produce other goods. On their own, these two first factors of production cannot, however, give rise to any production. Only their use by humans can lead to economic production. Despite this observation, economic production is defined as a function of these three factors for which it is possible to construct a mathematical relationship between the quantities produced (outputs) and the various factors (inputs) combined to obtain it. Since it is obligatorily in time, the previous observation leads to the question of the time/production ratio. This question is old! It requires, in our opinion, an analysis different to that which is the most traditionally proposed. Production is an action (or a displacement). Therefore, it can apparently be defined as a space traversed by a unit of time, i.e., as a speed. We then write:

$$
\text { Production }=\text { Product/unit of time }
$$

This equation is not acceptable. Indeed:

- if the production is null, the product is also null and vice versa;

- if the positive production is multiplied by a positive number, the product is multiplied by the same number and vice versa.

These two proposals are not verified for the speed of an object moving in a given space. If the movement is null, it is not sure that the speed is also null, it is enough that the time of the movement is null. Similarly, multiplying the speed does not give any results if it is not applied in a time. Production should not be considered as a speed. In other words, as usually defined, production has a dimension in time since it is the product of a speed by its application time. However, if the instantaneous speed is calculated at the limit, by the path travelled in an infinitely small time, the reasoning is circular since the space travelled is predefined. Economic variables do not move over time in a similar way to themselves.

If we define production according to its supposed factors, it is impossible to locate the productive activity in time. Conversely, if we decide to study production in terms of time, it is no longer possible to relate it to its supposed factors. To analyse economic production, it is essential to study its finalisation (instantaneous) and its progress (in continuous or continuum time) separately.

\footnotetext{
${ }^{3}$ For some productions, nature even takes care of it.
} 


\section{The Production}

To study the relationship of events to time in the basic sciences, and in particular the physical sciences, it is customary to contrast continuous time (the "passing time") with discontinuous time. The first allows us to study the phenomena that always exist during the period studied. After dividing the continuous time into discrete intervals, the second one allows to analyse the phenomena that appear at the end of "jumps". They are called this because initially, corresponding to the first interval, nothing happens, then, in a single movement; the phenomenon appears and persists in the following intervals. To the extent that apparently economic actions, and therefore production, "consume time" since they start at a time $t_{0}$ and end at a time $t_{n}$, logically economists have based their analyses on these two "forms" of time and most often on discontinuous time.

What is the proposed analysis? First, it is a question of identifying periods in the continuous time that facilitate the analysis: the month, the year, the period of financing, of depreciation... Then, this division makes it possible to take account of the fact that to produce it is necessary to undertake a series of actions in $t_{0}$ which finally ends at a time $t_{n}$ located at a finite distance of $t_{0}$. Therefore, production extends from $t_{0}$ to $t_{n}$ while being constantly null in this interval. It becomes positive only in $t_{n}$. Thus, perceived production cannot be assimilated to the time elapsing between $t_{0}$ and $t_{n}$ since the action defined in this period remains null until it becomes positive.

First null and then instantly positive, production appears to be a noncontinuous phenomenon that can therefore be analysed in discontinuous time. To be convinced, let us take up the examples proposed above. A computer without a screen is not a computer, an uncut rib of beef is difficult to eat, the first stones of a dam are not a dam, an interrupted sporting event must be replayed. In a word, a semi-product, a product divided by the number two is no more a product than a $1 / 3,1 / 4$ or $1 / 6$ th of a product. This observation is hardly debatable. However, another interesting question concerns the result, the fruit of this production. Is there a "trace" of the product in continuous time? In other words, can the production of one object serve as a "basis" in the production of another object? For example: once a first computer has been completed, can it be used materially in the production of another computer? Even if for some productions an experimental effect is possible, it is obvious that it will only be useful for a new production. Certainly, the first computer will be a source of increased utility for its owner but the physical production of the second computer will start from scratch. Thus, economic production appears as a specific action that:

- takes place in continuous time, between $t_{0}$ and $t_{n}$, and,

- ends at a moment $t$, the moment of its finalization.

\section{The Finalization of the Production}

According to the above, schematically, any production process can be represented as follows (Figure 1): 
Figure 1. Stages of Production

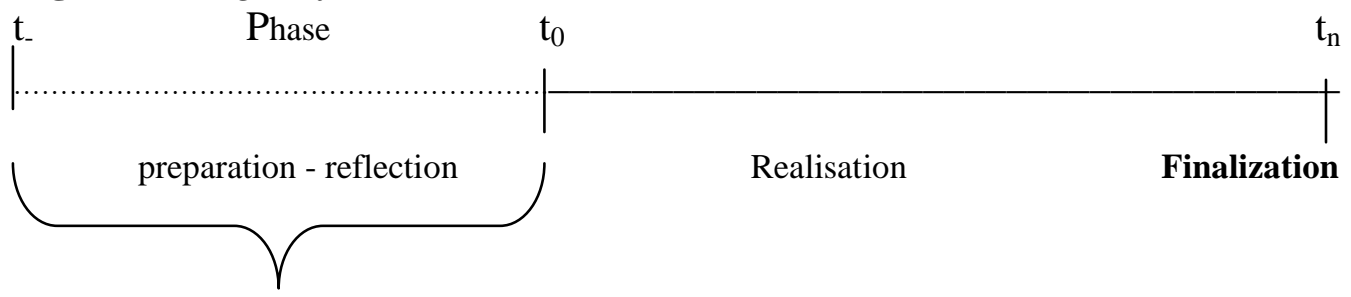

To fully understand this diagram, let us take the example of the manufacture of a computer. Using the available components and the assembly plan drawn up in the preparation-reflection phase, the workers assemble the various components from $t_{0}$ to $t_{n}$. During this time, all the actions carried out by the workers lead to the desired result. Each gesture is particular to the production of the computer, as we have already noticed, and is a continuous action over time. However, until the computer is finished, finalized, it does not exist. Literally, it only appears at the precise moment of its completion. So how can these two findings be taken into account simultaneously? In one way only: by considering that economic production is an undulating phenomenon. A wave that is a coming and going. However, only an instantaneous comeback gives an account of the dual reality of production:

- the production ranges from $t_{0}$ to $t_{n}$, so it must go through this time,

- the production is only located at the point $t_{n}$, so it must be in $t_{n}$ even during the journey from $t_{0}$ to $t_{n}$,

- the only solution - but it is entirely satisfactory - is in the recognition of the wave nature of production: at the point $t_{n}$, production is a wave, a movement in time, observed from $t_{n}$ to $t_{0}$ and identically from $t_{0}$ to $t_{n}$ (Schmitt 1984, p.58).

Let us take again the example of the production of a computer. It is a tangible asset. The material necessary for its manufacture is therefore preserved: nothing has been created and nothing is lost in the production process ${ }^{4}$. Naturally the computer is more useful to the man once it finished. The computer was first conceived, thought out, by the engineers in charge of its design, then manufactured by the workers in order to provide a useful tool for its users during its period of use. Producing therefore necessarily means thinking and working for useful purposes, or, to use Schmitt's definition, (1984, p.445): "to flow a matter (or energy) into a preconceived utility form".

The demonstration that production is a wave phenomenon is abstract. However, it does not allow any exceptions. Whatever it is, the production is first null in the realization phase and then becomes positive at the point of its finalization. Thus, not only it appears at the end of the realization phase but disappears at the precise moment when it becomes positive. The analysis of economic production must take these two aspects into account, so its study cannot take place in discontinuous (or continuous) time but in "quantum time" (Schmitt 1984, p.439). Production "quantifies time" (Schmitt 1984, p.440). Thus, any

${ }^{4}$ It is the same with energy. 
product is a quantum of time measured by the quantized time. This confirms the observation that only human work is truly productive: only human action to understand how additional utility can be obtained is productive. This is also the case in the production of a sports show.

To make the transition to our next part, let us now focus more specifically on the case of the production of a sports show. After the reflection-preparation phase required for its organization, a sports show, a football match for example, starts at "kick-off" $\left(\mathrm{t}_{0}\right)$ and ends $\left(\mathrm{t}_{\mathrm{n}}\right)$ about 90 minutes later. Each technical gesture made by the players can be considered as quantum of action, i.e., as a finite number of instant indivisible actions ${ }^{5}$. In addition, since each quantum is instantaneous, so is the sum of quanta. Nevertheless, the match takes place in continuous time. If the kick-off is not given it does not exist. If the match is interrupted it is not the announced show. Once again, apparently there is a contradiction: how can the same action be both instantaneous and extended in time? The only solution is that the production (of the sports show here) is the action that quantifies the continuous time. Indeed, once the final whistle is pronounced the match does not extend. As the match stops at the final whistle, the production of the sports show is ultimately positive neither during the duration of the match (see above) nor once it is over. Unlike material goods that seem to have a longer life expectancy, several decades for a dam, for example, a sporting event has no positive inertia over time, its value disappearing at the point when the result of the match is known and endorsed. In fact, this is a general result. Indeed, if a computer for example, has a lifetime or a value of use (a utility) of several years, its exchange value is defined by the corresponding quantum of time that is not material.

There are nevertheless several differences between the production of a material good and the production of sports shows ${ }^{6}$. In addition to the necessary cooperation of several actors on which we will return, unlike other productions, the sports shows take place in a predetermined period of time by the sports rules (football), or conditioned by the achievement of the expected result (tennis), but for which the interest and therefore the value lies in the knowledge of the final result. Moreover (Bouvet, 2011, p.12):

- the conditions of production are perfectly codified: producers must respect precise rules,

- most of the particular conditions of production are known,

- the quantum if actions conferring its value on production are partially identified.

Thus, a sports show can ultimately be precisely defined as the technical gestures that contribute to the quality of the show, which is useful for spectators and viewers (production), produced collaboratively in a pre-determined context

\footnotetext{
${ }^{5}$ If they were not instant, they would have an extension in the continuous time and would therefore be divisible.

${ }^{6}$ If one, nevertheless wishes to equate sports shows with an "economic good", three characteristics must be noted: it is a rival good for which there is no obligation of use but possibilities of congestion.
} 
(preparation-reflection), in the goal of obtaining a result whose value disappears at the end of the match (finalization).

\section{The Features of the Production of Sports Shows}

\section{Organization of Production and Competitive Balance}

Like any production, the production of sports shows begins with a reflectionpreparation phase in which producers imagine how they can best meet the needs of potential consumers. In sports economics, the emphasis is most often placed on two of the organizational characteristics of this production. First, the joint nature of production (Gayant 2016, p.15): unlike other live shows, the production of a sports show requires the presence of several competitors, simultaneously or successively. Moreover, even if the revenues related to media coverage are now the most important, mediatized sports shows are derived products (Andreff 2012, p.115) from direct sports shows that take place in stadiums. For televised sports shows, in the reflection-preparation phase, three main actors are therefore required to cooperate to produce: competition organisers, players and their agents and broadcasters.

The organizers' reflection focuses on the calendar, design and implementation of the competitions and therefore of the matches. The definition of the calendar is a difficult exercise to try to reconcile as intelligently as possible the constraints of the stakeholders. Thus, a sports calendar must be fair, minimize the risk of injury, take account of weather hazards, audience opportunities, and the calendar of international competitions. The design of competitions is in most sports a legacy from the past. Thus, depending on the sport and country, competitions can be organised in the form of championships, cups, pools, etc., including play-offs or not. Nowadays, the choice of competition design is very largely determined by the organisers' desire to maximise their direct (access rights plus TV rights) and indirect profits (sponsorship revenues and derived products). The implementation of competitions is ensured by the sports authorities themselves (national and international federations, leagues) or by companies specialised in the organisation of sporting events. It is then up to them to define the marketing strategy, draw up budgets, communicate, ensure the security of the event, find sponsors, take care of the logistics, etc.

Top athletes, who are the real productive force of sports shows, before matches, prepare technically, physically and mentally to be as efficient as possible. In this phase, the choice of coaches often proves to be a decisive element of success.

Broadcasters, depending on their strategy, position themselves to acquire the rights to sporting events likely to generate the best audiences. Then they broadcast the competitions.

This brief overview of the multitude of elements involved in the production of a television sports show might suggest that it is not always possible to bring them together. Between organizers and players, organizers and broadcasters and even 
sometimes between players and broadcasters, conflicts sometimes appear. Nevertheless, all of them most often meet around a common objective: to arouse a permanent interest among the final consumers, the viewers and spectators. Several factors can contribute to this interest. Since the pioneering work of Rottenberg (1956), actors and analysts have come together on one of them: uncertainty is one of the common denominators of this interest. And, to preserve this uncertainty, the players or teams that meet, must be of a comparable level. In other words, we must ensure that a certain competitive balance is maintained.

Competitive balance is one of the key concepts of the sports economy, and indeed one of the only ones that is truly specific. Even if it can only be measured ex-post, it must necessarily be considered ex-ante, during the preparationreflection phase of production. There are many definitions of competitive balance (Kringstad and Gerrard 2007) and multiple ways to measure it (Groot 2008). At our scale, the production of a sports event, the most commonly used indicator (Andreff 2012, p.165) is:

$$
\text { Competitive Balance }(\mathrm{CB})=\mathrm{L}_{\mathrm{ij}}=\mathrm{t}_{\mathrm{i}} /\left(\mathrm{t}_{\mathrm{i}}+\mathrm{t}_{\mathrm{j}}\right)
$$

Where:

- $\mathrm{L}_{\mathrm{ij}}$ an indicator of the level of the teams ${ }^{7}$.

- $t_{i}$ is the quantity of talent of the club $i$, approximated by the percentage of past victories of the club,

- $t_{j}$ is the quantity of talent of the club $j$, approximated in the same way.

Six main criticisms are addressed relative to this issue. In Europe, can the question of competitive balance be considered independently of the financial health of clubs (Andreff 2009)? In promotion/relegation models, are these opportunities not the most important determinant of its existence (Noll 2002)? Are differences in local potential not an important source of competitive imbalance (Helleu and Durand 2005)? Isn't the reputation of the teams even more decisive in the eyes of fans (Czarnitzki and Stadtmann 2002)? When the team that clearly dominates the competition is supported by many fans, can't the satisfaction they feel compensate for the weakness of the competitive balance (Szymanski 2001)? More fundamentally, why is it so rarely empirically validated (Andreff 2009)? Obviously, interest in sports events also depends on other factors. It is this observation that has led other authors (Kingstard and Gerrard 2004, Scelles and Durand 2010) to introduce into the literature the concept of competitive intensity, defined as: "the degree of competition within the league (or tournament) with respect to its price structure" (Kingstard and Gerrard 2004). This concept already makes it possible, and will undoubtedly make it possible even more so, depending on its future developments, to go beyond certain limits of competitive balance. Nevertheless, it does not refer to a particular match, and has the disadvantage of not taking into account the events, the quanta of action, necessary for the

\footnotetext{
${ }^{7}$ The ranking compared between the two teams at the point of the match and the bets placed with the bookmakers as to the outcome of the match are also a possible indicator.
} 
realization of the production which are carried out by the players and participate in the quality and the "exceptionality" of the show.

\section{Quality of the Show and "Competitive Exceptionality"}

In most cases, the authors who were interested in the notion of quality of sports performances did so in an attempt to assess the influence of this variable on the behaviour of viewers and spectators, particularly with regard to stadium attendance (Garcia and Rodriguez 2000). To estimate this variable, they distinguish between:

- the supposed or expected quality of the teams at the beginning of the season. To do this, they study the clubs' budgets, the players' salaries (considered as indicators of their productivity), the number of international selections of players composing the teams, etc.

- the current level of the team, approximated by the number of home wins in the last three games, the number of goals scored in the last games, the ranking, etc.

By doing so, the expected quality of the match is estimated ex-ante based on ex-post variables. In this case, quality is therefore essentially approximated by the means used to obtain it and the performances recently achieved. The implicit assumption associated with this reasoning is that teams that develop sports facilities and/or achieve good results produce a quality show. Is this systematically the case? No. Sometimes prestigious teams that base their success on defensive strategies offer a poor quality of show. The tactical choices of coaches can lead teams to neutralize each other. Paralysed by the stakes, some players or teams do not always succeed in expressing their talent. But one of the elements that underlie the interest of viewers and spectators is precisely the quality of the gestures made by professional athletes. This is even one of the main differences with many other sectors of activity: the elementary acts of production that take place in the continuum are of interest to others (sports fans) than those who realize them (players). The indirect consequences of this particularity are well known: starification, importance of remuneration, commercial use, financial drifts etc.

At this stage of the reasoning, a question arises: why are these actions of interest to others? The answer is no longer any doubt. If millions of people are interested in the elementary acts of production carried out by high-level athletes it is because they recognize them as exceptional. In other words, it is because the champions can perform unique and exceptional "technical gestures" and in any case, out of reach of amateur practitioners, they arouse admiration. Thus, the "quality of the show" is largely based on the nature of the technical gestures, the precision of actions, and the inventiveness of top athletes. In order to appreciate the quality of a match, rather than to estimate it by past performances, we therefore think, in addition to the competitive balance indicator, that it is interesting to propose an indicator of "competitive exceptionality". 
Beyond the performances that can be achieved by top athletes ${ }^{8}$, it is the percentage of successful technical gestures and the permanence of these actions during the match that allow opposing the professional players to amateurs. Such an indicator can therefore take the following form:

$$
\begin{aligned}
& \mathrm{CE}_{\mathrm{xp}}=\sum \sum\left[\left(\mathrm{PSA}_{\mathrm{pro}}-\overline{\mathrm{PSA}}_{\mathrm{ama}}\right)+\left(\mathrm{DSA}_{\text {End }}-\mathrm{DSA}_{\text {Beginning }}\right)\right] \\
& \mathrm{J}=1 \quad \mathrm{a}=1
\end{aligned}
$$

where:

- $\mathrm{CE}_{\mathrm{xp}}$ : the competitive exceptionality indicator,

- J: The number of players making teams. Equal to 2 for individual sports,

- PSA $A_{\text {pro: }}$ the percentage of successful selected actions, i.e. successful technical gestures (passes, shots, stops ...) by the professional players,

- $P_{\text {PAma: }}$ the average percentage of comparable actions that amateur players achieved,

- DSA End: the difference between the percentages (means) of the successful actions at the end of the game by the professional players and the amateur players,

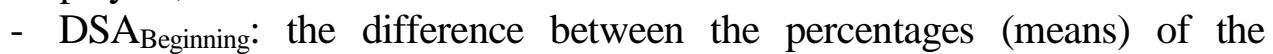
successful actions at the beginning of the game by the professional players and the amateur players.

Using the statistics collected by the companies OPTA or PROZONE, for example for a football match, $\mathrm{CE}_{\mathrm{xp}}$ could be obtained by the following 7 steps:

1) by calculating, for each of the players participating in the match and for each action selected, the difference between the percentage of success for the professional player studied and the average percentage of success for an amateur player,

2) by summing the differences obtained $=A$,

3) by calculating the difference between the percentages (means) of the successful actions at the end of the game by the professional players and the amateur players $=\mathrm{B}$,

4) by calculating, the difference between the percentages (means) of the successful actions at the beginning of the game by the professional players and the amateur players $=\mathrm{C}$,

5) by summing the differences obtained $=D$,

6) for each player by adding $A$ and $D=X$,

7) at last, by calculating $C E_{x p}$ by adding the sum of the $X s$ for each of the players on the field.

\footnotetext{
${ }^{8}$ On a match, it is not uncommon for a "small team" to compete or even eliminate a more prestigious team. Exceptionally an amateur player can perform a fantastic technical gesture.
} 
Estimating this indicator therefore implies being able to obtain some statistics that are currently widely produced by companies specializing in this sector of activity and to agree on the average level of performance among amateur athletes. This is not easy but not impossible ${ }^{9}$. In our opinion, the advantage of such an indicator would be to be able to supplement the indications provided by the $\mathrm{CB}$ calculation: the competitive balance. However, it is not yet entirely satisfactory. Why? Because in an even more visible way than in other sectors of activity, the value that can be ex-post attributed to the technical gestures made during a meeting is conditioned by the result of the match and even more by the consequences of this one and therefore by its competitive stakes.

\section{Results and Competitive Stake}

All economic production takes place first in continuous time but acquires its final value only at the precise moment of its finalization. For any good at this moment the value of exchange or the product in the exact sense of the term leaves room for the product value of use. For a sports match at the precise moment of the final whistle, the (technical) actions that contributed to the realization of the match turn into a result that often leads to a proofreading of the "game facts" observed during the match. This is a perfect illustration of the wave nature of production. The elementary production gestures (passes, dribbles, shots, etc.) made by the players during the match are at the origin of the result (coming) but at the same time it illuminates them differently (going). Economically, the production of a sports spectacle is thus also a wave movement, in other words a "coming and going" between the beginning of the match and the precise moment when the result is known and endorsed. An important question arises: what elements can lead to a particular appreciation of what happened during the match? In the professional sport it is about the consequences of the result obtained. Let us take a "stylised" example. In a football match where the loser is eliminated counting for an international competition, the referee validates the goal of a player scored while he was offside. The match ends 1-0.

The sporting and economic consequences of this elimination usually lead to reinterpreting this arbitration error as being the cause of the negative consequences for the losing team. In some cases, such a reading of the situation has even led a club president to file an attack on the referee in court (Italy) or his murder (Colombia). However, by definition, what one can lose or gain as a result of a particular enterprise corresponds to a precise notion: the notion of stake. Also, to appreciate the importance of the final result of a sporting event and thus the retrospective reading of the elementary actions of production requires in the sporting field to know what the consequences that can result from it are.

From a theoretical point of view, introducing the notion of stake indirectly amounts to introducing the notion of risk into the reasoning. To explore this question further, the use of risk and uncertainty theory (Knight 1921, Allais 1984, Pradier 2006) could therefore most certainly prove useful in the future.

${ }^{9}$ We performed these calculations for the French league 1, the English Premier League and the Spanish Liga. The results will be presented at a conference in Paris in 2020. 
Another perspective also seems possible: that of establishing a "table of competitive stakes". Based on the observation that the competition stakes is conditioned by past, present and future elements, such a table could be built in three stages consisting of:

- to "graduate" the factors influencing the issue of sports confrontations,

- to examine their simultaneity,

- to associate coefficients (weight) to the different distinguished situations.

The history of the confrontation may be characterized by a very significant cultural context (case of derbies), by recent one-off events (injury, arbitration errors, conflict between managers) or by the absence of any particular antagonism between the two clubs. The prestige of confrontation (present) finds its origin at several levels: exceptional character, important international dimension, rarity, context, etc. Finally, future consequences play an important role by definition. Classified in order of increasing involvement, can be distinguished: the continuation or maintenance in competition, the existence of sporting and economic consequences, the existence of economic or sporting consequences.

Therefore, by associating a multiplying factor to the different scenarios considered, it becomes possible to define the table of competitive stakes mentioned above. This one presents a double interest:

- it allows to associate a weight to the confrontations, a "friendly regional" confrontation being the one with the least stakes in this respect,

- it allows, subject to obtaining certain information very widely available in the specialized press, to predict the level of competitive stake of a match.

In this way, the notion of a competitive stake differs from the notion of sporting stakes usually presented in the literature (Jennet 1984, Borland 1987, Cairns 1987) where it appears to be the opportunity offered to teams to obtain the results necessary to achieve pre-determined objectives (title or accession to a qualifying place). In addition to its quantitative dimension, in our opinion its main interest, in addition to the indicator of competitive balance (which mainly relates to the preparation-reflection phase of a sports shows) and the competitive exceptionality indicator (allowing to appreciate the particular character of the elementary gestures realized during the production phase), is to make it possible to quantify the "importance of the result" which materialises the instantaneous finalization of this type of production, and thus to contribute to a better appreciation of the value of sports shows. 


\section{The Valuation of Sports Shows}

\section{The Necessary Amortization of the Specific Costs of Production}

Beyond the necessary collaboration of the various stakeholders in the preparation-reflection phase, the production of a sports show also requires cooperation in its implementation phase. Three or four actors are systematically involved: the organizer of the competition, the (two) teams or players who compete and, when it is televised, the broadcaster. This necessary cooperation can be schematised as follows (Figure 2):

Figure 2. Cooperative Process of Producing a Sports Show

1

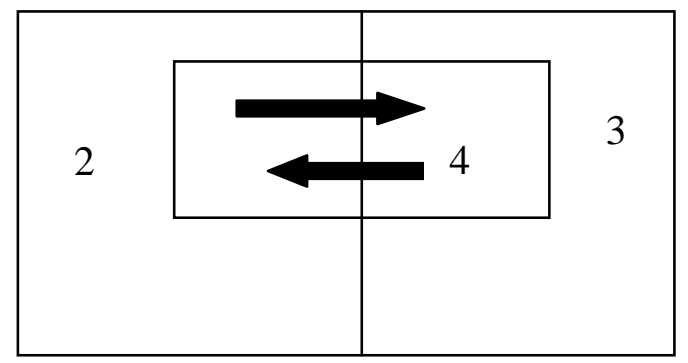

The competition organizers determine the rectangle 1: the "framework" in which the match will take place: place, date, rules, refereeing conditions, etc. The clubs that meet (rectangles 2 and 3 ) choose the production factors: preparation, team composition, substitutes, etc., who will participate in the confrontation (4). Broadcasters retransmit this one: choice of the type of retransmission, comments, analyses, etc. For example, in the extreme case where a club organizes a "friendly match" between their team "A" and their team "B" not televised, 1, 2 and 3 become one. Nevertheless, in all cases, the organization of such a match generates production costs that must be amortized.

The concept of depreciation is a notion that, from Adam Smith to some contemporary theoreticians of production, has attracted the attention of many authors. It corresponds to the need to "offset" the investments made to implement a production through a creation of equivalent value. Also, organizers must get a remuneration covering their organizational costs, producers their participation costs and broadcasters their broadcasting costs. At its core, an interest in the question of production costs therefore raises questions about the conditions for expressing the value created and its measurement. Measuring production by its utility is not satisfactory: if, by definition, a product has a certain utility, it is not a physical quantity but an immeasurable psychological quantity. Measuring production by counting for the time required to complete it also leads to a stalemate. By measuring the time during which work is done, we measure time and not work: the measurement is physical but not economical. Such a measure supposes the existence of a unit of work while only one unit of time is available. Only the introduction of money can solve the problem of measurement in 
economics. The production of sports shows is no exception. If it is possible to assign a value to this product it is because it is monetized. Here again, this monetization has three remarkable characteristics.

\section{Exhibition, Monetization and Commercial Methods}

About thirty years ago, when a West German viewer asked someone: "Can you explain to me why you earn three million marks a year when I, as a locksmith, only earn 30,000?" a German football player replied with a mathematically logical formula: "It is because in Germany there are 300,000 locksmiths and only 300 football professionals" (Bouvet 1996, p.125). According to this answer, it would be because footballers have rare skills that they are extremely well paid. Today this answer no longer holds. In some sports and other sectors of activity, workers with extraordinary skills do not earn millions. So nowadays, when a neurosurgeon asks himself this question, a football player could answer: "it's because I'm on TV!"”

This is one of the particularities of "sports work":

- the nature of the sport practised, individual or collective, most often determines the status of the sports worker, employed or self-employed,

- most professional sports activities are not accomplished in the public sphere but also in public.

It is mainly because millions of viewers are interested in the feats of their favourite champions that some of them, precisely those whose productions are widely covered by the media, receive very high levels of remuneration. At first glance, this exchange seems to be able to be analysed as a relative exchange in which these high levels of remuneration are the counterpart of the exceptional performance achieved. Nevertheless, spectators and viewers do not directly remunerate professional sportsmen. The transaction is monetized. In other words, when a sports fan decides to sacrifice part of his income to "consume a sports show" he exchanges a levy right on the national product acquired through his direct or indirect participation in the production against an access right to the sports show. This transaction should rather be analysed as the "absolute" exchange of a right into another right. Therefore, the question arises of the conditions of monetization of the production of sports shows. And, again, the study of the chronology of operations is rich in lessons.

What do the producers of sports shows market? Except for the case of player trading in which a sports club decides to sell one of its factors of production that does not fall within the scope of our analysis, the answer is now well known. Producers of sports shows sell rights of four natures. Exhibition rights: rights sold in exchange for the highlighting of a name, a brand, a product. Access rights: entrance fees to stadiums. Broadcasting rights: rights that allow broadcasters to market the produced images. Naming rights ceded following naming operations. When are these rights commercialised? There too, and even in the limited case of 
access rights ${ }^{10}$, they are before the matches. This exchange should not be schematised as below using two reciprocal arrows representing a concomitant movement:

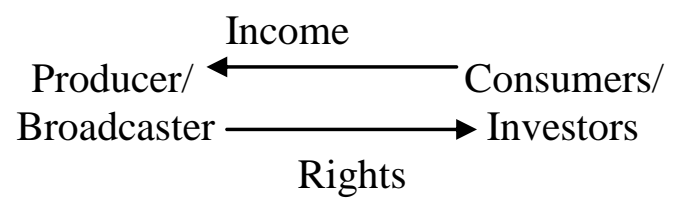

Moreover, this representation is not acceptable for another reason: the rights transferred are used to finance the production of sports shows. In other words, the monetization of professional sport is based on pre-financing authorized by the sale of rights (Bouvet 2016, p.53). Rather, it should be represented schematically as follows (Figure 3):

Figure 3. Monetization of Sports Shows

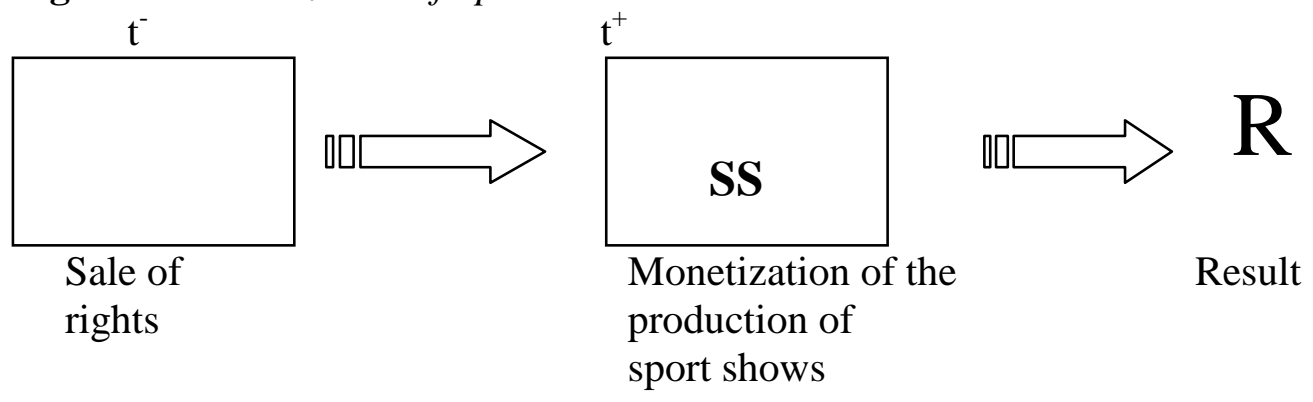

Thanks to the sale of multiple rights, sports shows can take place. Their realization gives an object to the transferred rights which confers on them their final monetary value. At the point when the match ends, it disappears to give way to a series of numbers that expresses the result of the match. Sports rights have no intrinsic value. It is their association with the production of sports shows that creates it. This is anticipated by of rights buyers (viewers, spectators, sponsors, media, advertisers, etc.). It disappears when the show ends.

Finally, a last question deserves our attention: how are these rights marketed? They are also specific. For exhibition rights, because for many sponsors it is a particularly profitable communication technique, for access rights, because the capacities of sports venues are limited, for broadcasters and companies wishing to sign a naming contract, because they are exclusive, a call for competition is launched. The procedure for allocating retransmission rights is the best illustration of this. These are awarded according to the auction technique. The sports broadcasting rights are assigned at the end of a procedure allowing the owner of the property (single and indivisible) who wishes to sell it, to select the buyer from among several candidates (Cohen and Mougeot 2001). In this type of procedure,

\footnotetext{
${ }^{10}$ Logically sports clubs want to have many "subscribers" who then participate in the prefinancing of production.
} 
the seller's objective is usually to obtain the highest possible transfer price ${ }^{11}$ and therefore largely explains the amount of the contracts. For the allocation of sports broadcasting rights, submission under sealed envelopes is the technique most often used. For now, it is well suited to all actors because it has several practical advantages $^{12}$ and does not discourage buyers because of the quadruple potential utility of the result of sports confrontations.

\section{The Quadruple Utility of the Result}

All production finds its purpose in the utility that it provides to consumers. Generally, the target consumption is final consumption; consumption that allows satisfying needs of different kinds. Traditionally, this first form of consumption has been opposed to productive consumption: the utility of the initial production results then from the investments allowed by it. According to Attali and Guillaume (1990, p.131), final consumption influences well-being through three components:

- a utility component, which groups together what the product allows to achieve,

- a communication component, which allows each of us to integrate or differentiate,

- an imaginary component that allows one to escape, to dream, to transgress etc.

To these first three forms of consumption is added a productive component that aims to obtain delayed effects. On most of their purchases, consumers seek to combine these different components. The choice of a car makes it possible to satisfy a need of transport but can also make it possible to be integrated in a family of consumers (BMW) and for certain models to escape (cabriolet). When this vehicle is used as a working tool then it also has a productive function.

As we have seen, the purpose of the production of sports shows and therefore its utility lies in the result. However, it is symptomatic to realize that in this case the various stakeholders will be sensitive to the components mentioned above. The communication and imaginary components are the most important for sports fans ${ }^{13}$. Through the results of their teams and favourite players they feel valued, recognized, integrated and sometimes manage to forget their daily lives. For the

\footnotetext{
${ }^{11}$ However, it is not the only one. Other objectives can be sought: choose the buyer, influence the conditions of use of the property sold.

${ }^{12}$ The four main ones are:

- when the candidates are sensitive to the risk of losing the auction, each of them increases its bid to increase its probability of winning the bet;

- it makes it possible to fight against agreements between candidates;

- it gives the possibility to make an offer without having precise information on the price ready to pay by the buyers;

- it places buyers in perfectly transparent conditions.

${ }^{13}$ In some cases, this is also true for investors.
} 
players the utility is more direct. Depending on the results, their remuneration and "ratings" may or may not increase.

For the organizers, the results justify the implementation of the production: the more "exceptional" they are, the easier it is to justify the existence of these events, which for them are a source of significant profits. Finally, for broadcasters, the results influence the profitability of their investments. Thus, for a television channel holding the image rights to a sports competition, the qualification of the national team is synonymous with important audiences that can be paid for by advertisers. Similarly, the presence of "his" team in an important competition ensures sponsors a wide audience.

In the field of sport, "results" take on considerable importance because their "retroactive" effect is tangible. Depending on the people concerned, they justify a symbolic investment (fan), personal (player) or economic (organizer and broadcaster). The production of sports shows only exists at its completion while requiring a series of actions taking place in the continuous time. Nevertheless, the result of the match, the score, has no time dimension. The production of sports shows is indeed a "flux-reflux". Although it requires exceptional technical gestures that can only be carried out by high-level producers (flux), it is only finalised at the point of the final whistle, when it is transformed into a number that retroactively confers a certain dimension (reflux).

\section{Conclusion}

Works dealing with the production of sports shows most often emphasize the joint nature of this production. Many authors nevertheless consider that such a living spectacle can be analysed as the fruit of the combination of several factors of production. In our opinion, it is now necessary to complete these analyses taking account of the "wave" dimension of this production. Like any production after the phase of "preparation-reflection" in which it is necessary to ensure that certain conditions (competitive balance), it takes place in the continuous time and ends at a precise moment. As summarized in Table 1, it thus presents "universal" characteristics, but also several singularities that condition very largely its monetization.

Insofar the various stages of its production are perfectly defined and lead to a quantifiable result, the production of a sports show is a sort of "stylised illustration" of more complex production phenomena. In "sports times", defined by the sports rules (the duration of a match for example), qualified technical gestures are made (competitive balance) which, not only arouse the interest of many fans, but also lead to a result to which it is possible to associate a precise number (competitive stake). To shed light on it in its entirety, the analysis must necessarily take account of the three in-dissociable stages that make it possible to define this production (which is not the case if we reason in terms of factors of production). To do this end, the concepts of competitive exceptionality and competitive stake should in the future make it possible to complete the work on competitive balance. The first can only be calculated ex-post. The second can be approximated ex-ante. 
Its final calculation is however more easily ex-post. Beyond these technical difficulties, several ideas introduced in this reflection: use of the two new proposed indicators, analysis of sports and economic stakes using risk theory, study of the specific conditions of monetization using pre-financing through the sale of rights should most certainly be developed in the coming years by other researchers. In any case, that is our wish.

Table 1. Synthesis

\begin{tabular}{|c|c|}
\hline Universalities & Singularities \\
\hline $\begin{array}{l}\text { - Several temporal divisions can } \\
\text { be distinguished } \\
\text { - The production of a sports show } \\
\text { is a wave phenomenon } \\
\text { - The production of a sports show } \\
\text { is preceded by a phase of } \\
\text { "reflection-preparation" } \\
\text { - The actions contributing to the } \\
\text { realization of the production } \\
\text { take place in the continuous } \\
\text { time } \\
\text { At the point of its finalization, } \\
\text { the sports show is transformed } \\
\text { into a "special useful form": the } \\
\text { result of the match }\end{array}$ & 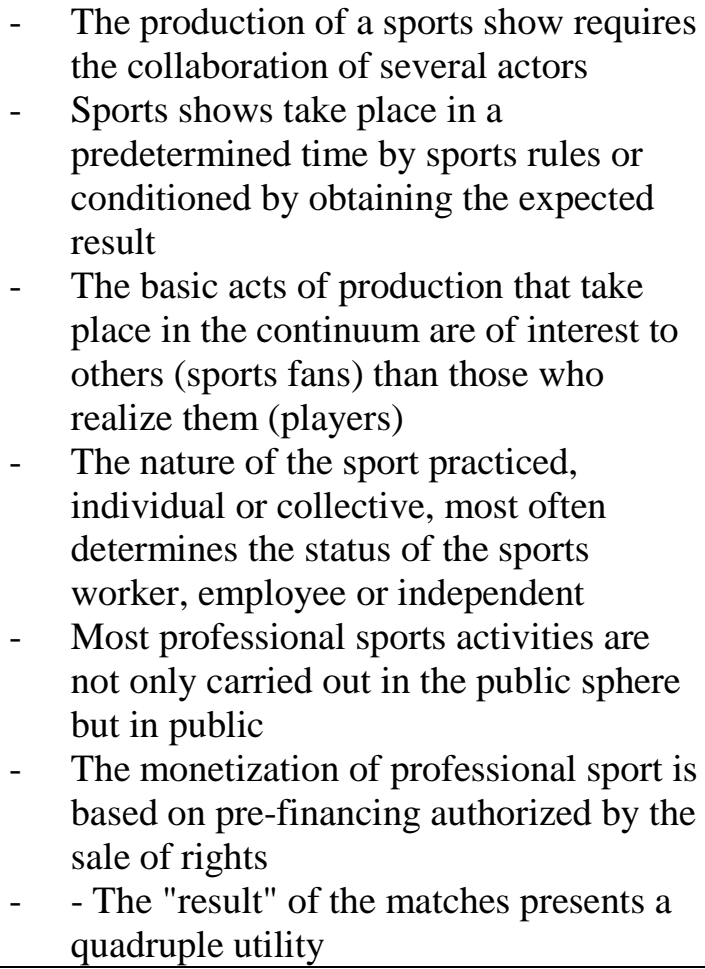 \\
\hline
\end{tabular}

\section{References}

Allais M (1984) The credit mechanism and its implications. In Arrow and the Foundations of the Theory of Economic Policy, GR Feiwel (ed), MacMillan Press.

Attali J, Guillaume M (1990) L'anti-économique. [The anti-economic]. Paris: PUF.

Andreff W (2009) Equilibre compétitif et contrainte budgétaire dans une ligue de sport professionnel. [Competitive balance and budget constraint in a professional sports league]. Revue Economique 60(2): 591-634.

Andreff W (2012) Mondialisation économique du sport. [Economic globalization of sport]. Bruxelles: De Boeck.

Borland J (1987) The demand for Australian rules football. Economic Record 63(182): 220-230.

Borland J (2006) Production functions for sporting team. In Handbook on the Economics of Sport, W Andreff, S Szymanski (eds), 610-615. Cheltenham/Northampton: Edward Elgard. 
Bouvet P (1996) Les salaires des vedettes du sport professionnel par équipe: une application privilégiée de la théorie du salaire d'efficience? [The wages of the stars of the professional team sport: a privileged application of the theory of the salary of efficiency?] Revue Française d'Economie XI(4): 119-144.

Bouvet P (2011) Que valent les compétitions sportives? Une nouvelle piste de réflexion. [What are sport competitions worth? A new avenue of reflection]. L'Actualité Economique 87(2): 205-222.

Bouvet P (2016) L'économie du sport professionnel: regards alternatifs. [The economics of professional sports: alternative looks]. Saarbrücken: PAF.

Cairns JA (1987) Evaluation changes in league structure: the reorganization of the Scottish football league. Applied Economics 19(2): 259-275.

Cohen E, Mougeot M (2001) Enchères et gestion publique. [Auctions and public management]. Paris: La Documentation Français.

Czarnitzki D, Stadman G (2002) Uncertainty of outcome versus reputation: empirical evidence from the first German football division. Empirical Economics 27(1): 101112.

Echaudemaison CD (1996) Dictionnaire d'économie. [Dictionary of Economics]. Paris: Nathan.

Garcia J, Rodriguez P (2000) "The determinants of football match attendance revisited empirical evidence from the Spanish football league. Journal of Sports Economics 3(1): 13-38.

Gayant JP (2016) Economie du sport. [Sport economics]. Paris: Dunod.

Groot L (2008) Economics, Uncertainty and European Football: Trends in Competitive Balance. Cheltenham: Edward Elgar.

Gustafson E, Hadley L, Ruggiero J (1999) Alternative econometric models of production in major league baseball. In Sports Economics: Current Research, J Fizel, E Gustafson, L Hadley (eds), 95-107. Westport: CT, Praeger.

Helleu B, Durand C (2005) L'équilibre compétitif des ligues ouvertes européennes. Une analyse démographique des promotions/relégations: performances vs présences. [The competitive balance of the European open leagues. A demographic analysis of promotions / relegations: performances vs presences]. In Recherches Actuelles en

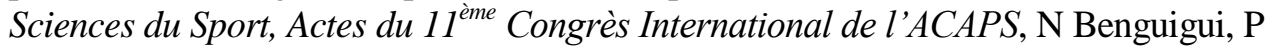
Fontayne, M Desbordes, B Bardy (eds), 735-736. Paris: XI Orsay.

Jennet N (1984) Attendances, uncertainty of outcome and policy in Scottish league football. Scottish Journal of Political Economy 31(2): 176-198.

Knight FH (1921) Risk, Uncertainty, and Profit. Boston and New York: Houghton Mifflin.

Kringstad M, Gerrard B (2004) The concept of competitive balance and uncertainty of outcome. International Association of Sports Economists Conference Paper, 0412.

Kringstad M, Gerrard B (2007) Beyond competitive balance. In International Perspectives on the Management of Sport, T Slack, M Parent (eds), 149-172. Burlington: Elsevier.

Noll R (2002) The economics of promotion and relegation in sports leagues: the case of English Football. Journal of Sports Economics 3(2): 169-203.

Pradier PC (2006) La notion de risque en économie. [The concept of risk in economics]. Paris: La Découverte.

Rottenberg S (1956) The baseball players' labor market. Journal of Political Economy 64(3): 242-258.

Scelles N, Durand C (2010) Competitive intensity of professional sports leagues: Between measured and perceived realities. $2^{\text {nd }}$ European Conference in Sports Economics, 5.10.2010-6.10.2010. Cologne, Germany.

Schmitt B (1984) Chômage, inflation et malformations du capital. [Unemployment, inflation and capital malformations]. Albeuve/Paris: Economica/Castella. 
Scully G (1974) Pay and performance in major league baseball. American Economic Review 64(6): 915-930.

Smith A (1776) An inquiry into the nature and causes of the wealth of nations. London: W Strahan and T Cadell.

Szymanski S (2001) Income inequality, competitive balance and attractiveness of team sports: Some evidence and a natural experiment from English soccer. The Economic Journal 111(469): 69-84. 